\section{Uma semioticista: entre a teoria e a paixão}

\section{A semiotician: between theory and passion}

Norma DISCINI (USP) normade@uol.com.br

Recebido em: 17 de dez. de 2019. Aceito em: 05 de fev. de 2019.

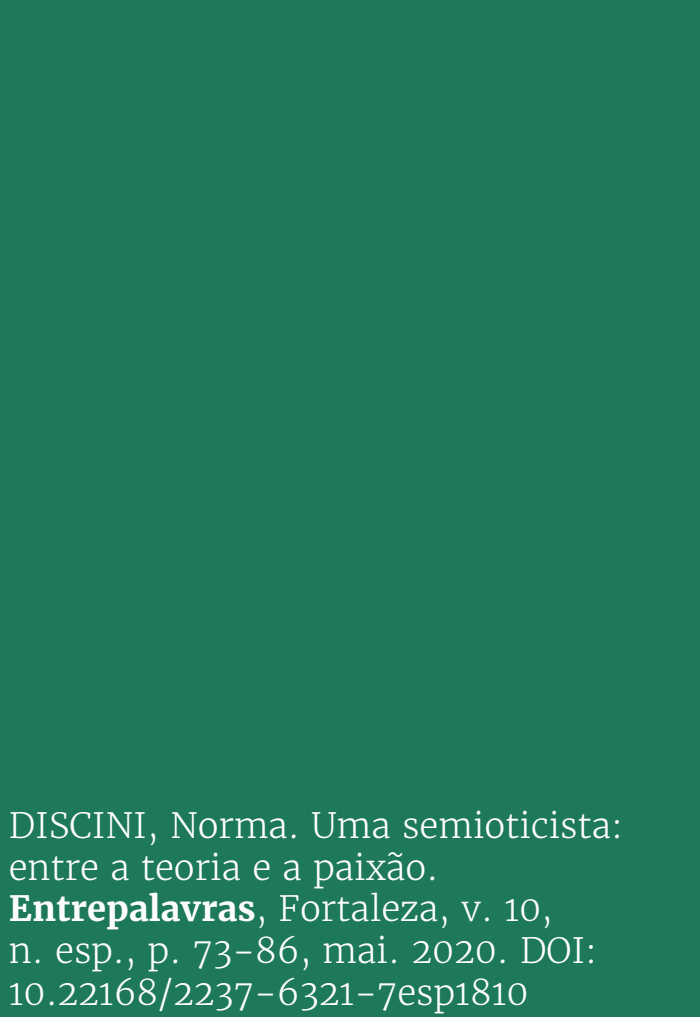

10.22168/2237-6321-7esp1810

Resumo: O Dicionário de Semiótica (GREIMAS; COURTÉS, 2008, p. 324), após definir o mundo natural como uma "estrutura 'discursiva"" que se apresenta no quadro da relação sujeito/ objeto, acrescenta que esse mundo "é o enunciado construído pelo homem e decifrável por ele [o próprio homem]". Há uma semioticista brasileira que leva os leitores de sua obra a um desvelamento peculiar do que "está aí" feito semiose. Queremos homenagear essa intelectual, cuja obra desbastou campos inimagináveis para nossa percepção, e cujo comportamento nos levou a querer passar "além do Bojador". Falamos de Diana Luz Pessoa de Barros. O desejo de reverenciar a pensadora e de reconhecer sua força moral em nossas vidas sempre será maior do que o poder de nossas palavras. Entretanto, movidos pela memória do brilho que vem de lá, ou do lugar da própria Diana, procuraremos falar sobre alguns dos princípios que fundamentam sua obra, como a atenção à figuratividade e à ideologia concebidas como não separadas das tensões do afeto. Enquanto isso, tentamos entrar em conjunção com o objeto de valor que ela oferece a quem dela se aproxima: a vontade de viver articulada por um 
10 (esp.)

73-86 mai. 2020

"querer extenso". É um querer que, longe de recuar diante de alguma impossibilidade, alimenta-se pelo próprio não-poder, como está previsto por Greimas e Fontanille (1993) em estudo feito sobre a obstinação.

Palavras-chave: Semiótica. Homenagem. Ideologia. Paixão.

Abstract: The Dictionary of Semiotics (Greimas; Courtés, 2008, p. 324), after defining the natural world as a "discursive" structure that presents itself in the frame of the subject/object relation, adds that this world "is the utterance built by man and decipherable by him [man himself]". There is a Brazilian semiotician who takes readers of her work to a peculiar unveiling of what "is there", made semiosis. We want to pay a tribute to this intellectual, whose work has cleared unimaginable fields in order to help our perception, and whose own conduct has led us to want to go "beyond the limits". We are talking about Diana Luz Pessoa de Barros. The desire to pay reverence to the thinker and to acknowledge her moral strength in our lives will always be greater than the power of our words. However, moved by the memory of the brilliance that comes from there, or from the place of Diana herself, we shall try to talk about some of the principles that underlie her work, such as attention to figurativity, and ideology conceived as not being separate from the tensions of affection. In the meantime, we try to come into conjunction with the object of value which she offers to those who approach her: the will to live articulated by an 'extended will". It is a wish that, far from retreating when confronted by some impossibility, feeds on its own non-power, as envisaged by Greimas and Fontanille (1993) in a study on obstinacy.

Keywords: Semiotics. Tribute. Ideology. Passion.

\section{Éthos e ator da enunciação}

Diana Luz Pessoa de Barros apresenta-se no interior de sua obra conforme determinado éthos, já que, a partir do exame de seus escritos, depreende-se um modo de dizer que remete a um modo de ser. Junto à significação enunciada mediante o crivo teórico desponta o modo de ser da intelectual. Do saber-fazer desponta o "ser" da semiocista, o que implica o saber-ser. Greimas e Fontanille (2014) assim preveem essas relações:

[...] o saber-fazer, separado da pressuposição que o liga ao fazer e ao seu êxito, é interpretável como constitutivo do "ser" do sujeito, e esse ser é por sua vez considerado como modalizado (é a "maneira de ser enquanto se faz") sob a forma de um saber-ser (GREIMAS; FONTANILLE, 2014, p.17).

O livro que cravou definitivamente no Brasil os fundamentos da semiótica discursiva, Teoria do Discurso (BARROS, 2002), desvela de modo peculiar, para o leitor, a semiose do mundo. As peculiaridades do dizer recorrentes no conjunto de obra tão prolífera confirmam a identidade autoral conforme um efeito de identidade. Esse efeito se vincula a uma das características do éthos: "É o éthos (caráter) que leva à persuasão, quando o discurso é organizado de tal maneira que o orador inspira confiança" (ARISTÓTELES, 1991, I, 1356a). 
A recorrência do modo de dizer apresenta a "maneira de ser enquanto se faz". A autora se firma como um actante enunciador, que, adensado semanticamente, compõe-se como ator da enunciação. Sustento do estilo, o ator da enunciação se apresenta mediante uma voz, um tom de voz e um caráter, o que se ampara na noção discursiva de éthos herdada da retórica aristotélica (MAINGUENEAU, 2008; DISCINI, 2015; 2016; FIORIN, 2008). Entre a retórica, a estilística e a semiótica, desponta o ator da enunciação como éthos e como estilo, o que foi desenvolvido por Barros (2014) no âmbito da literatura.

A semioticista emerge dos seus escritos no desempenho do papel actancial de enunciador e do papel temático de produtor dos próprios textos. O papel temático, conceituado como a "representação, sob forma actancial de um tema ou de um percurso temático" (GREIMAS; COURTÉS, 2008, p. 496), implica o tema da produção (BARROS, 1985; 2002) e a "gestualidade" própria à condução do tema ao longo da totalidade da obra.

O tema da produção, instalado no campo dos estudos semióticos, apresenta-se, com Barros, engendrado por determinado "acento de sentido". É um acento que, como elemento de concentração de intensidade da própria semiose (TATIT, 2019a), aparece na obra da autora, seja em pontos de fruição estética viabilizados junto ao objeto analisado, seja na crítica ao "monopólio da verdade", apontado como contraponto da própria fruição estética.

O acento, que forja uma direção para a observação do mundo, aparece em estudo feito pela semioticista sobre mecanismos de construção do sentido na pintura. Entretanto, em meio ao realce dado à dimensão do sensível instaurada por "figuras da expressão" e à recriação poética do mundo daí decorrente, Barros (2019a), na análise feita de um quadro de Van Gogh, não dá as costas para a crítica social. O social se confirma no interior do olhar semiótico. A polêmica constitutiva dos discursos é legitimada no enfrentamento com a ideologia ou com o "ponto de vista" do senso comum¹.

Na progressão do trabalho, ao conceituar as "figuras de expressão" como componentes do semissimbolismo, a autora declara, como ponto de partida para suas reflexões, estudos feitos por Jean Marie Floch $(1981 ; 1985)^{2}$. Ela faz ver que, contrariamente aos sistemas

\footnotetext{
${ }^{1}$ No mesmo estudo, a autora (2019a) contempla como o semissimbolismo, na sua função de "figura da expressão", manifesta-se em textos sincréticos.

2 Selecionamos apenas duas entre as citações de J. M. Floch, feitas por Barros (2019a).
} 
10 (esp.)

73-86 mai.

2020

de símbolos, os sistemas semissimbólicos são caracterizados não pela conformidade entre as unidades do plano da expressão e do plano do conteúdo, mas pela correlação entre categorias pertencentes aos dois planos.

Os Girassóis, de Van Gogh, é a pintura analisada (BARROS, 2019a), no realce concedido a tais "figuras do plano da expressão", que, formadas "na relação entre a expressão e o conteúdo" (p. 32), compõem o semissimbolismo. Ao ampliar os fundamentos postulados pelo semioticista do visual, Barros não só identifica, na natureza morta estetizada pelo quadro, a correlação entre claridade e formas pontiagudas e o sentido vida, entre obscuridade e formas arrendondas e o sentido da morte, mas também faz ver as tensões que tais relações estabelecem.

Para as tensões, a autora evoca a semiótica tensiva desenvolvida por Zilberberg (2006). Ela reconhece como da ordem da extensidade a relação entre o amarelo escuro e as formas arredondadas, expressão da morte, e como da ordem da intensidade, a relação entre o amarelo claro e as formas pontiagudas, expressão da vida. No exame das oscilações tensivas a analista identifica, lá, o que se distingue por uma duração alongada; cá, o que se distingue por uma duração abreviada. A duração breve entendida como pontual é reconhecida como alinhada ao que é mais sensível.

A semiocista (BARROS, 2019a) ressalta que as "figuras da expressão" estabelecem novas relações sensoriais entre a expressão e o conteúdo, enquanto criam "efeitos de leitura do mundo entre a novidade e a estereotipia cultural" (p. 33). A novidade é apontada no engendramento das relações semissimbólicas, que, segundo Barros, destituem o senso comum de seu "monopólio de verdade" (p. 33-34), enquanto recriam o mundo na dimensão do sensível.

Pensar o mundo "entre a novidade e a estereotipia cultural", vinculando o segundo termo a um "monopólio da verdade" a ser desestabilizado pela crítica, constitui marca forte da enunciação na obra de Barros. Em outro estudo (BARROS, 2010), ao descrever mecanismos de construção do sentido de anúncios que propagam o produto oferecido por determinados bancos, a autora veladamente denuncia o preconceito contra determinados segmentos da sociedade. A "sensibilidade mais aguçada aos valores emocionais e sensoriais", tal como interpretada pelo senso comum e pelas pesquisas de opinião, pode ser lida como menos prontidão de reflexão e crítica: 
Essas estratégias são empregadas principalmente nos anúncios que se dirigem ao público mais jovem, às mulheres, aos aposentados, às camadas menos prestigiadas da sociedade a que o senso comum e as pesquisas de opinião atribuem sensibilidade mais aguçada aos valores emocionais e sensoriais (BARROS, 2010, p. 13).

No estudo em que Barros (2019a) examina um quadro de Van Gogh, constatamos que, se lá ela nomeia a estereotipia para negá-la como valor e princípio ético, a inclinação para valorar valores próprios ao senso comum e recusá-los firma-se como determinada "disposição" ou devir. Negar valores dados e propor outros no lugar daqueles projeta o "belo gesto" (GREIMAS; FONTANILLE, 2014). Assim se configura uma entre outras marcas da enunciação enunciada no conjunto dos escritos de Barros. Por meio de tais marcas reconstituímos o ato enunciativo e o éthos do enunciador.

Num exame geral da obra da semioticista, se nos deslocarmos do estudo feito sobre a pintura para o trabalho desenvolvido junto ao discurso político pautado pela intolerância (BARROS, 2016a; 2016b; 2016c), teremos condições de interrogar se o "belo gesto" de fato permanece como constitutivo da totalidade discursiva. Em caso afirmativo teremos condições de acompanhar como tal gesto compõe o estilo entre um artigo e outro, um capítulo e outro e assim por diante. A recorrência de um modo de dizer, para ser apreendida como condição de engendramento de um estilo, não necessita da totalidade numérica dos textos reunidos sob a mesma assinatura. De um único texto ou do excerto de um único texto emerge a totalidade discursiva, na qual se radica o ator da enunciação concebido como "Baudelaire, enquanto se define pela totalidade de seus discursos" (GREIMAS; COURTÉS, 2008, p. 45). A totalidade que compõe um estilo radica-se numa estrutura - aberta, porém, à historicidade do mundo. No que diz respeito ao trabalho de Barros, nossa hipótese é a de que o gesto de acentuar a historicidade no interior do discurso semiótico é um dos componentes do "belo gesto", que compõe seu estilo.

\section{Do gesto ao "belo gesto"}

Concebido segundo seu estatuto semiótico, isto é, pensado na relação entre a expressão e o conteúdo que o constitui, o gesto, como componente de um "discurso gestual" (GREIMAS, 1975, p. 59), é identificado pelo autor entre práticas dessemantizadas e atividades 
10 (esp.)

73-86 mai. 2020

míticas ou simbólicas, estas entendidas como de gestualidade (re) semantizada. Segundo Greimas, lá o fazer é prioritário e cá a prioridade é o desejar. O semioticista opõe "a caça do elefante, considerada no seu conjunto como atividade prática, à dança no povoado que se prepara para a caça, considerada (a dança) como atividade mítica" (p. 64). A dança se inclina à (re)semantização dos gestos conforme o mesmo estudo.

Examinadas no âmbito da enunciação, a gestualidade prática se apresenta conforme uma comunicação "direta" e efetiva, porque se cumpre nos seus fins de convencimento, enquanto a atividade mítica se define como "uma intencionalidade transformadora do mundo como tal" (GREIMAS, 1975, p. 65). A dança "em si não é um espetáculo que procure comunicar um sentido aos espectadores, não é nem mesmo um fazer objetivo" (p. 65).

Barros (2010) reinterpreta as operações de (re)semantização e de dessemantização gestuais previstas pelo autor de Sobre o Sentido e faz isso por meio da incorporação do conceito de movimentos tensivos (FONTANILLE; ZILBERBERG, 2001). Ao movimento tensivo descendente, a autora vincula a dessemantização, e ao ascendente, a (re)semantização. Lá a autora reconhece um "aumento da extensão do programa gestual projetado e um enfraquecimento da tensão afetiva devido à diminuição da carga semântica dos movimentos gestuais" (p.3). Na direção ascendente, base da (re)semantização, Barros reconhece "um aumento da tensão afetiva por causa de uma espécie de tomada de consciência 'semântica' de cada gesto que forma o programa gestual 'carregado de sentido'" (p. 3). Acessar o esquema tensivo para entender os sentidos dos gestos, tal qual fez Barros (2010), é recurso que converge para a noção de "formas mistas da gestualidade, onde o mítico se encontra difuso no prático e vice-versa" (GREIMAS, 1975, p. 65). Estamos no âmbito da coexistência e da interdependência entre grandezas ou da correlação entre elas.

Se a correlação entre os movimentos tensivos constitui condição de engendramento deles (ZILBERBERG, 2006), o critério analítico de acessá-los para entender os sentidos dos gestos pode ser incorporado na descrição de estilos. É o caso do estilo autoral que emerge do interior do discurso científico em geral e do discurso semiótico em particular.

No discurso semiótico, como convém ao rigor científico, instauram-se os movimentos descendentes, que atenuam o ímpeto da subjetividade. Juntamente com as coerções relativas ao efeito de objetividade e de distanciamento do enunciador em relação ao enunciatário, o contrato de fidúcia, amparado na verdade científica, 
projeta a perspectiva de contemplação distanciada em relação ao objeto. Tatit (2019b), ao falar sobre o tema "Semiótica do acento e da velocidade", lembra que a linguagem científica tem por princípio desfazer a força do acento, entendido aí como componente do plano do conteúdo dos textos. Entretanto, do "menos do menos" (ZILBERBERG, 2012, p. 67) do "acento de sentido", ou do quase zero da tonicidade requerida pelo tom da voz teórica, criam-se condições para o restabelecimento do ímpeto do afeto. Esbarra-se na "gestualidade mítica". Favorecido o "acento de sentido", que faz o sensível irromper em meio à inteligibilidade científica, o contrato de confiança chega a evoluir para um discurso confidencial (GREIMAS, 2014).

Ao observar "a proximidade semântica que existe entre a confiança nos homens e a confiança em suas palavras", Greimas (2014, p. 142) reconhece a possibilidade de espessamento da confiança e explica: É "como se a veracidade do discurso aumentasse à medida que faz passar seus conteúdos subentendidos e velados" (Idem). Transposta para o exame feito do discurso semiótico, a noção de intensificação da confiança, tal qual sugerida por Greimas, é comparável ao princípio que sustenta o "belo gesto" na elaboração dos saberes científicos sustentados conforme determinado paradigma teórico.

Argumentativo como qualquer outro, o discurso semiótico, desenvolvido entre o fazer persuasivo e o fazer interpretativo, requer o "enfraquecimento da tensão afetiva da 'carga' semântica", o que foi apontado por Barros (2010, p. 2) para o "programa gestual prático" (e que deslocamos para o exame do fazer científico). Se aceitarmos que há no discurso semiótico, como em qualquer outro, as tensões entre o sensível e o inteligível, afirmamos que, no prenúncio da ascensão do sensível, projeta-se a passagem da confiança para a confidência, como sugeriu Greimas (2014).

Os "conteúdos subentendidos e velados", conforme diz Greimas, apreensíveis como componentes da acentuação da tonicidade nos trabalhos de Barros, fazem o "acento de sentido" firmar-se não apesar do rigor - da análise e da formalização teórica - próprio ao estilo da semioticista, mas justamente por meio desses parâmetros. A autora assim procede, seja ao promover o preenchimento das lacunas constitutivas do discurso da arte, do que sobressaem as postulações renovadoras sobre o conceito de semissimbolismo, seja no trabalho junto ao discurso político reproduzido da mídia contemporânea, entre outros estudos. 
10 (esp.)

73-86 mai.

2020

A autora impregna de ímpeto sensível o discurso semiótico principalmente ao iluminar a dimensão histórica do objeto contemplado. Ela assim procede (BARROS, 2002, p. 148 - 152), ao fazer emergir a "dialética interna do signo", esta que "não se revela inteiramente a não ser nas épocas de crise social" - como a própria semioticista nos autoriza a pensar, a partir de citação feita do pensamento de Mikhail Baktin (1981, p. 47). Se a citação do pensamento do teórico russo alça o valor de argumento de autoridade para fundamentar a relação entre discurso e ideologia ressaltada pela autora, a própria semiótica, sob o estilo de Barros, cumpre-se política e ideologicamente. Isso acontece notadamente mediante o robustecimento da visão crítica a respeito da intolerância e do discurso intolerante.

Em trabalho intitulado Todos tenemos prejuicios, pero no todos discriminamos. Reflexões sobre o discurso intolerante, Barros (2016c) distingue, entre as "discussões mais presentes na imprensa e nos demais meios de comunicação no Brasil" - as que dizem respeito ao "direito à liberdade de pensamento" e à "expressão do preconceito" (p. 283). Como argumento, Barros insere, em meio a seus comentários, a citação da voz do sujeito intolerante. Colocada entre aspas para demarcar a heterogeneidade mostrada e marcada (AUTHIER-REVUZ, 1982), a formulação figurativa, desenvolvida na voz do discurso intolerante, reforça o impacto provocado no leitor.

Barros (2016c) destaca como exemplo dos debates acirrados sobre a intolerância "a escolha do deputado Marco Feliciano para presidir a Comissão de Direitos Humanos e Minorias da Câmara dos Deputados" (p. 283). Assim prossegue:

De um lado, se colocaram os que, por julgarem racistas e homofóbicas muitas das declarações do deputado, consideravam que ele não tinha condições de ocupar posto na Comissão de Direitos Humanos e, muito menos, de presidi-la. De outro, os que insistiam em que o deputado tinha direito de pensar e dizer que "Africanos descendem de um ancestral amaldiçoado" e que "O caso do continente africano é sui generis: quase todas as seitas satânicas, de vodu, são oriundas de lá. Essas doenças, como a Aids, são todas provenientes da África", e de defender que psicólogos possam anunciar tratamento para a homossexualidade. Nesse caso, os que queriam que, por isso, ele deixasse a presidência da Comissão, é que seriam intolerantes (BARROS, 2016c, p. 283).

Ao excerto segue a reprodução de uma notícia, cujo título é "Chamado de racista, Marco Feliciano manda prender manifestante" (p. 284). A formulação figurativa privilegiada na citação do discurso do outro 
restabelece a acentuação tônica da voz da analista. O leitor é convocado, não explicitamente, a ajustar-se ao sensível, que, recrudescido, faz o relato ascender em tonicidade. A ilusão da transparência da significação incorporada pelo discurso do senso comum e princípio gerador do preconceito (CHAUí, 1996/1997, p. 116) sustenta as falas preconceituosas. Isso é rejeitado veladamente pela ética do discurso semiótico estabelecido. Eis o gesto, que, equiparado a uma atitude como foi postulado por Greimas (1975), está na circunvizinhança do "belo gesto" definido por Greimas e Fontanille (2014, p. 13). Os autores apresentam-no como "uma sequência de comportamentos particularmente enigmática para o semiocitista: ao mesmo tempo conclusiva e inaugural, símbolo de uma moral, mas também de uma preocupação estética" (p. 13).

Citando o autor de Semântica estrutural, Barros (2019b) lembra que o discurso, longe de ser somente o lugar de encontro do significante e do significado, é "o lugar de distorção de significação provocada [...] pelas oposições das forças divergentes da inércia e da história" (GREIMAS, 1976, p. 57). Da voz de Greimas encadeada à de Barros subentende-se que a história nasce do enfrentamento com a inércia.

Se Fontanille (2015, p. 73) destaca que o "belo gesto" reabre o devir e a diversidade de seus possíveis e que, diante disso, anula o efeito de imobilidade suscitado pelo dever, instalando concomitantemente "um querer indeterminado" e um sujeito "claramente autônomo e autodestinado" - entendemos por que o "belo gesto" irrompe na continuidade do discurso semiótico e particularmente no estilo da semioticista. No mesmo trabalho (BARROS, 2019b), após aludir ao "desvelamento veridictório da mentira", problematizado junto às fake news, a autora afirma: "Essas questões são fundamentais para fazer de nossos alunos e da sociedade em geral bons leitores dos textos, sobretudo da internet."

\section{Estilo de vida e paixão}

Sob a experiência estética que reconstrói os grandes descobrimentos realizados pelo povo português, em especial as conquistas feitas de longínquas terras, por mar, ao longo do século XVI, Fernando Pessoa (1988-1935) nos lança em meio a uma interpelação dirigida ao próprio mar: Valeu a pena? - a que segue a resposta: Tudo vale a pena, se a alma não é pequena. O poeta completa: Quem quer passar além do Bojador, tem que passar além da dor (PESSOA, 1965, p. 82). Se 
10 (esp.)

73-86 mai.

2020

nós nos aliarmos às figuras retóricas, diremos que Diana Luz Pessoa de Barros ou simplesmente Diana favorece ao outro a percepção do sal, próprio às grandes conquistas: Ó mar salgado/ quanto do teu sal/ são lágrimas de Portugal! - disse Fernando Pessoa.

Se, na semiótica, procurarmos meios para entender o fenômeno, encontraremos as noções de semiocepção (BEIVIDAS, 2017), de ajustamento (LANDOWSKI, 2005) e de formas de vida (FONTANILLE, 2015), entre outras. As três noções partem da herança estruturalista da teoria da significação, desenvolvem-se mediante perspectivas próprias e chegam a resultados diferentes. Entretanto, pertencentes ao discurso semiótico, elas são comparáveis. A título de hipótese - mais imaginativa do que conceitual - tentamos interpretar como se processa a impregnação sensível do comportamento de Diana na vida de seu interlocutor.

Com Beividas o fenômeno seria descrito por meio da semiocepção, concebida conforme o princípio de categorização linguística do mundo. A manifestação do sentido subsumida à imanência dele teria conduzido o valor que emerge da figura de Diana para nós. A semiocepção teria viabilizado a atenção para a "gestualidade" transformadora que promove a (re)ssemantização do que entendemos ser perfectivamente acabado.

A compreensão do papel de Diana no curso dos eventos teria sido fundada pela percepção constituída pela forma linguística, que organiza o sentido do mundo. A arbitrariedade do signo linguístico (Saussure) e da própria forma linguística (Hjelmslev), respaldo para "o enunciado construído pelo homem e decifrável por ele [o próprio homem]", teria amparado a apresentação do fenômeno. A hipótese parece apresentar alguma compatibilidade com a noção greimasiana de simulacro (GREIMAS, 2014, p. 238). Conforme uma semiose alargada, logo não necessariamente presa a objetos semióticos dados e acabados, a semiocepção nos teria trazido, ao longo das idas e vindas das interações com Diana, seu "belo gesto".

Com Landowski obteríamos condições para interrogar, fronteiriço com o acaso, o ajustamento com determinado "estilo de vida". Como se estivéssemos numa dança em que o risco e a busca pelo equilíbrio são equipolentes teríamos incorporado o "belo gesto" como um "operador de transformação ética" (GREIMAS; FONTANILLE, 2014, p. 13). Deslocando nossos corpos da programação, aliada da ilusão do controle sobre a vida, o ajustamento teria promovido para nós a abertura dos possíveis: os possíveis que se legitimam pela iminência do imprevisto ou do acidente (aléa). 
Fontanille (2015, p. 69 - 73) ressalta que o "belo gesto" participa das formas de vida. Antes disso postula que as formas de vida se constituem como "organizações semióticas ('linguagens') características de identidades sociais e culturais, individuais e coletivas" e que por isso são consideradas "constituintes imediatos das semiosferas" (p. 26). O autor dá o dandismo como exemplo.

Ao fazer tais asserções, Fontanille, no mesmo estudo (2015) traz como ilustração a balada "A luva", de Schiller³. A história do cavaleiro desafiado a provar seu amor por uma dama da alta corte - tendo para isso, de atirar-se no fosso dos leões, em que a luva fora lançada pela própria dama - expõe, para negá-la eticamente, determinada "forma de vida". Aludindo ao tema cravado no espírito cavalheiresco como dimensão subjacente à narrativa poética, Fontanille destaca um gesto particular, classificado como o "belo gesto". O autor sugere que as formas de vida suscitadas pelo gesto desencadeado compõem-se mediante singularidades identificáveis na valoração imprimida no valor do imprevisto. É um imprevisto nomeado em língua francesa com o adjetivo "extrême" (FONTANILLE, 2015, p. 70). O dicionário Petit Robert, entre outras acepções para "extrême", apresenta as de "animé", "rempli de passion".

O cavaleiro conseguiu realizar o ato heroico. Entretanto, em seguida e inesperadamente atira a luva no rosto da dama e diz: "Com vossos agradecimentos, Senhora, eu não me importo" - e se retira de modo brusco. O ato do cavaleiro se transforma em gesto ético, e o gesto em "belo gesto", conforme Fontanille (p. 71).

O semioticista, ao afirmar que estamos diante do deslocamento de determinado processo, pois o gesto do cavaleiro "interrompe a cadeia de trocas proposta pela dama e reforçada pelo público que testemunhava a cena" (Idem), enfatiza que o "belo gesto" dá início a uma nova sequência de atitudes submetidas a "outras regras, ainda indeterminadas" (Idem).

O autor de Formes de vie lembra que o "belo gesto" permite ao cavaleiro não só denunciar a moral "comercial" e social constituinte do gesto da dama, mas também organizar a contraposição a essa moral, firmando a possibilidade de uma ética individual (p. 72). O autor, que, a partir de Paul Ricoeur, distingue a ética da moral, lembra que, se do lado da moral confirmam-se as normas como sistemas de restrições, e mesmo como uma deontologia, a ética funda um "projeto de vida" (p. 73). O "belo gesto" é ético.

3 O termo "ilustração" foi empregado na acepção de argumento, tal qual exposto por Fiorin (2015, p. 188-189). 
10 (esp.)

$73-86$

mai.

2020

\section{Notas finais}

O comportamento de nossa homenageada, seja como semioticista, seja como figura "da vida", encoraja-nos a imprimir o "acento de sentido" num "querer extenso". Longe de recuar diante de alguma impossibilidade, esse querer alimenta-se pelo próprio nãopoder, conforme previsto por Greimas e Fontanille (1993) no estudo sobre a obstinação. Entretanto o "querer extenso" se transforma e se amplia pela incorporação do "belo gesto". Vem daí um "querer indeterminado", que compõe o sujeito "autônomo e autodestinado".

A semioticista, ou melhor, a morena sorridente que saiu de Monte Aprazível, empurra o sujeito a acolher como seus "o perigo e o abismo" desta vida. Em Mar Portuguez, de Fernando Pessoa, está registrado: Deus ao mar o perigo e o abysmo deu,/ Mas nelle é que espelhou o céu.

\section{Referências}

ARISTÓTELES. Rhétorique. Paris: Librairie Générale Française, 1991.

AUTHIER-REVUZ, J. Hétérogéneité montrée et hétérogéneité constitutive: élements pour une approche de l'autre dans le discours. DRLAV, 26. Paris, Centre de Recherche de l'Université de Paris, VIII, 1982, p. 91-151.

BAKHTIN, M. Marxismo e filosofia da linguagem. São Paulo: Hucitec, 1981.

BARROS, D. L. P. de. La coherence textuelle. In: PARRET, H. \& RUPRECHT, H. G. (Org.). Exigences et perspectives de la sémiotique. Recueil d’hommages pour A. J. Greimas. Amsterdam/ Philadelphia: John Benjamins, 1985, p. 273-281.

BARROS, D. L. P. de. Teoria do discurso: fundamentos semióticos. 3. ed. São Paulo: Humanitas, 2002.

BARROS, D. L. P. de. Os sentidos da gestualidade: transposição e representação gestual. Cadernos de Semiótica Aplicada, Araraquara, Vol. 8.n.2, p. 1-14, dezembro de 2010 (on line).

BARROS, D. L. P. de. Semiótica, Retórica e Estilística: alguns diálogos. In: Esther Gomes de Oliveira/ Suzete Silva (Orgs.) Semântica e Estilística: dimensões atuais do significado e do estilo. Campinas, SP: Pontes Editores, 2014, p. 247-262.

BARROS, D. L. P. de. Estudos discursivos da intolerância: o ator da enunciação excessivo. Cadernos de ESTUDOS LINGUÍSTICOS - (58.1), Campinas, pp. 7-24 - jan./abr. 2016a. 
BARROS, D. L. P. de . Le discours intolérant sur Internet : tension, signification et énonciation.. In: Sens et médiation. Congrès de l'Ássociation Française de Sémiotique., Luxemburgo - Actes du, congrès de l'Association Française de Sémiotique. Paris - França: AFS Éditions, 2016b. p. 281-290.

BARROS, D. L. P. de . Todos tenemos prejuicios, pero no todos discriminamos. Reflexões sobre o discurso intolerante. In: Diana Luz Pessoa de Barros. (Org.). Margens, periferias, fronteiras: estudos linguístico-discursivos das diversidades e intolerâncias. São Paulo: Editora Mackenzie, 2016c, v. 2, p. 283-294.

BARROS, D. L. P. de. Questions sur le semi-symbolisme et le syncrétisme en sémiotique. In: Sémir Badir; Maria Giulia Dondero; François Provenzano (Dir.). Les discours syncrétiques: poésie visuelle, bande dessinée, graffitis. Liège (Belgique). Presses Universitaires de Liège, 2019a, p. 31-40.

BARROS, D. L. P. de. Contribuições da semiótica para o estudo da sociedade. Palestra ministrada no XXV Colóquio de Centro de Pesquisas Sociossemióticas (1994-2019) na PUC-SP, $2019 b$.

BEIVIDAS, W. La sémiologie de Saussure et la sémiotique de Greimas comme épistémologie discursive: une troisième voie pour la connaissance. Limoges: Lambert-Lucas, 2017.

CHAUÍ, M. Senso comum e transparência. In: O Preconceito. Julio Lerner Editor. São Paulo: Imprensa Oficial do Estado, 1996/ 1997, p. 115-132.

DISCINI, N. Corpo e estilo. São Paulo: Contexto/FAPESP, 2015.

DISCINI, N. O estilo nos textos. 2ed. São Paulo: Contexto/FAPESP, 2016.

FIORIN, J. L. Em busca do sentido: estudos discursivos. São Paulo: Contexto, 2008.

FIORIN, J. L. Argumentação. São Paulo: Contexto, 2015.

FLOCH, J. M. "Sémiotique plastique et langage publicitaire". Documents, Paris, Groupe de Recherches Sémio-linguistiques, 111 (26), 1981.

FLOCH, J. M. Petites mytologies de l'oeil et de l'esprit. Paris,Amsterdam: Hadès-Benjamins, 1985.

FONTANILLE, J. Formes de vie. Liège: Presses Universitaires de Liège, 2015.

FONTANille, J.; ZILBERBERG, Cl. Tensão e significação. São Paulo: Discurso/Humanitas, 2001.

GREIMAS, A. J. Sobre o sentido. Ensaios Semióticos. Trad. Ana Cristina Cezar et alii. Petrópolis RJ, 1975.

GREIMAS, A. J. Semântica Estrutural. São Paulo: Cultrix/ Editora da Universidade de São Paulo, 1976. 
10 (esp.)

73-86

mai.

2020
GREIMAS, A. J. Sobre o sentido II. Ensaios Semióticos. Trad. Dilson Ferreira da Cruz. São Paulo: Nankin/ Edusp, 2014.

GREIMAS, A. J.; COURTÉS, J. Dicionário de Semiótica. Trad. Alceu Dias Lima et al. São Paulo: Contexto, 2008.

GREIMAS, A. J.; FONTANILLE, J. Semiótica das paixões. Dos estados de coisas aos estados de alma. Trad. Maria José Rodrigues Coracini. São Paulo: Ática, 1993.

GREIMAS, A. J.; FONTANILLE, J. O belo gesto. In: Edna M. F. dos Santos Nascimento; Vera Lucia R. Abriata (Orgs). Formas de vida: rotina e acontecimento. Ribeirão Preto (SP): Coruja, 2014. cap. 1, p. 13 - 33.

LANDOWSKI, E. Les intéractions risquées. Nouveaux Actes Sémiotiques. Limoges: Presses Universitaires de Limoges. n 101-103/2005

MAINGUENEAU, D. A propósito do éthos. Trad. Luciana Salazar Salgado. In: MOTTA, Ana Raquel; SALGADO, Luciana Salazar (Org.). Éthos discursivo. São Paulo: Contexto, 2008, p. 10-29.

PESSOA, F. Obra poética. Rio de Janeiro: Aguilar, 1965.

TATIT, L. Passos da semiótica tensiva. Cotia, SP: Ateliê Editorial, 2019a.

TATIT, L. Semiótica do acento e da velocidade. Palestra ministrada no XXV 2019b.

ZILBERBERG, Cl. Élements de grammaire tensive. Limoges: Pulim, 2006.

ZILBERBERG, CL. La structure tensive. Liège: Presses Universitaires de Liège, 2012. 